\title{
RORSCHACH: FLÂNEUR E ANTI-FLANÊUR
}

Tais Turaça Arantes

Gabriel de Melo Lima Leal

Ronaldo Vinagre Franjotti

\begin{abstract}
RESUMO
Analisaremos neste artigo a pertinência de uma comparação entre Rorschach, personagem da graphic novel Watchmen, de Moore e Gibbons, e a figura do flâneur segundo delineado por Baudelaire e pela leitura de Walter Benjamin sobre a obra deste. Concluímos a partir desta comparação que existem algumas diferenças para além das semelhanças entre o flâneur e a personagem de Gibbons e Moore.
\end{abstract}

Palavras-chave: Rorschach; Flâneur; Anti-Flanêur; Watchmen; Walter Benjamin.

\section{RORSCHACH: FLÂNEUR AND ANTI-FLANÊUR}

\begin{abstract}
In this article we analyze the pertinence of a comparison between Rorschach, character of the graphic novel Watchmen, of Moore and Gibbons, and the figura of the flâneur delineated by Baudelaire and Walter Benjamin's Reading of Baudelaire's work. We conclude from this comparison that there are some differences beyond the similarities between the flâneur and Gibbon's and Moore's chracter.
\end{abstract}

Keywords: Rorschach; Flâneur; Anti-Flanêur; Watchmen; Walter Benjamin

\section{Introdução}

Ao longo de seu percurso, as Histórias em Quadrinhos, doravante referenciadas como HQs, sofreram diversas modificações. Em suma, o marco inicial oficial das HQs é a publicação de Menino Amarelo, em 05 de maio de 1895,

Doutoranda em Psicologia Social da Universidade do Estado do Rio de Janeiro. Brasileira, residente em Rio de Janeiro- RJ. E-mail: taistania@gmail.com

Mestre em Letras pela Universidade Estadual de Mato Grosso do Sul. Brasileiro, residente em Campo Grande-MS. E-mail: gmlimaleal@gmail.com

Doutorando em Letras da Universidade Federal de Mato Grosso do Sul. Brasileiro, residente em Campo Grande - MS. E-mail: tutor.franjotti@gmail.com 
de autoria de Richard F. Outcault e, desse período até a década de 30, a abordagem temática das HQs era voltada para o cômico. Após esse início embrionário, houve as primeiras mudanças e veio a época que viria a ser conhecida como Era de Ouro.

Foi em 1929, ano da quebra da bolsa de Wall Street, que se deu o início a Era de Ouro das HQs. Foi nessa época que se definiu o conceito de super-herói. Heróis como Capitão América e Superman foram criados nesse período com fundamentação ideológica para completar as lacunas da sociedade norteamericana. Na década de 60, um novo conceito de herói se formou, e deu-se início à Era de Prata das HQs, pois o perfil dos leitores mudara e heróis mais humanizados surgiram.

Se, por um lado, na Era de Ouro, as personagens eram edificadas sob valores relacionados a questões políticas e ideológicas, eles também possuíam uma fundamentação mitológica. Em contraponto, a Era de Prata trazia heróis cujos valores eram ligados à ciência, o que refletia a sensação de iminência de uma guerra nuclear entre a URSS e os EUA. Exemplos de heróis dessa época são o Homem-Aranha e o Quarteto Fantástico.

A Era de Bronze surge na década de 70 e mostrou que as HQs continuavam em um fluxo histórico. O que aconteceu a partir de então foi que temáticas adultas, tais como abuso sexual e tráfico de drogas, começaram a ser introduzidas nas narrativas, além de haver, nesse período, a reconstrução de muitas personagens populares - como o exemplo do Batman, que teve a sua "obscuridade" trabalhada de forma mais intensa. Aqui ocorre também o apogeu de heróis e anti-heróis sem poderes - tais como Conan e Monstro do Pântano. Outro dado relevante que denota as mudanças desta era é que as personagens começaram a morrer dentro das narrativas - um exemplo é o caso de Gwen Stacy, a namorada de Peter Parker (Homem-Aranha).

Não há um marco estabelecido unanimemente para o fim da Era de Bronze, mas muitos estudiosos da área de HQs compreendem que o seu fim foi na década de 80, quando se deu inicio à Era Moderna, com as publicações Batman: 0 cavaleiro das Trevas e Watchmen.

Doutoranda em Psicologia Social da Universidade do Estado do Rio de Janeiro. Brasileira, residente em Rio de Janeiro- RJ. E-mail: taistania@gmail.com Mestre em Letras pela Universidade Estadual de Mato Grosso do Sul. Brasileiro, residente em Campo Grande-MS. E-mail: gmlimaleal@gmail.com

Doutorando em Letras da Universidade Federal de Mato Grosso do Sul. Brasileiro, residente em Campo Grande - MS. E-mail: tutor.franjotti@gmail.com 
A graphic novel' (GN) Watchmen surge nesse período pós-moderno, que Peccinini e Leite (2002, pág. 01) explicitam sob as condições de "um clima de incertezas e uma dificuldade de sentir ou representar o mundo", de tal modo que, "diante da sensação de irrealidade, da desordem e do vazio, a sociedade cada vez mais se individualiza e se torna apática". Dessa forma Moore e Gibbons elegem para serem trabalhadas temáticas que traziam em si questões polêmicas, como, por exemplo, o abuso sexual que uma das personagens sofre durante a narrativa.

O contexto de Watchmen se realiza em uma realidade alternativa, na qual existe a vitória americana na Guerra do Vietnã e a reeleição à presidência dos Estados Unidos de Richard Nixon. A trama tem início com o assassinato de um membro do grupo de vigilantes que nomeia a GN: o Comediante. Logo após isso, Rorschach, outro membro do grupo, levanta a suspeita de uma possível conspiração para matá-los todos e, a partir disso, a história começa a se desenvolver.

Os autores de Watchmen mostram sua ótica sobre heróis e como realmente seria o mundo com eles, pois os que aparecem na GN são tão caóticos quanto o mundo que tentam salvar. Um destes é a personagem que analisaremos nesse artigo: Rorschach. Um fato a ser destacado é que todo herói está dividido entre ser ele mesmo dentro da sociedade e ser o vigilante, por assim dizer. Dessa forma, deve permanecer em foco qual exatamente é a identidade que as personagens assumem para si. Conforme veremos à frente, no caso de Rorschach, há uma inversão da relação ego/alter ego. Kovacs, a identidade verdadeira de Rorschach, fica relegada a um segundo plano. O cidadão passa a ser o disfarce do justiceiro, e não o contrário.

1 Graphic novel é o termo utilizado para se referir as histórias de longa duração, é o análogo na arte sequencial. Geralmente seus temas trabalham questões diversas, tais como: violência, homossexualismo, caos, entre outros e atingem mais o público adulto. O termo ficou popular com Will Eisner.

Doutoranda em Psicologia Social da Universidade do Estado do Rio de Janeiro. Brasileira, residente em Rio de Janeiro- RJ. E-mail: taistania@gmail.com

Mestre em Letras pela Universidade Estadual de Mato Grosso do Sul. Brasileiro, residente em Campo Grande-MS. E-mail: gmlimaleal@gmail.com

Doutorando em Letras da Universidade Federal de Mato Grosso do Sul. Brasileiro, residente em Campo Grande - MS. E-mail: tutor.franjotti@gmail.com 


\section{RORSCHACH}

Devemos levar em consideração na análise, não somente a personagem ao longo do graphic novel (GN) e o que nos é mostrado dela em primeiro plano, mas também, a partir daí, a parte da sua rotina que, mesmo não estando explícita na GN, se torna, até certo ponto, dedutível. Sobre Rorschach, Held $(2009,29)$ nos explica que ele

carrega um fardo terrível. Ele viu a verdadeira face da cidade. Ele viu este mundo cheio de vermes, pelo que ele é: uma vala dos desgraçados, cada um escalando as costas de seus vizinhos por nada mais que um prazer insignificante, para simplesmente continuar essa vida patética por um segundo, um minuto, um dia a mais.

Rorschach passa os dias se dividindo entre ser Rorschach e ser Kovacs, um lunático propagandista do apocalipse que, justamente por o ser, não é levado a sério - principalmente em termos de suspeitas com relação às atividades desempenhadas por Rorschach. Em determinado momento da narrativa, enquanto o vigilante está sendo capturado pela polícia, ele grita quando the arrancam sua máscara: "Não! Meu rosto! Devolva!" (MOORE; GIBBONS, 2009, 170).

Kovacs é o disfarce de Rorschach, não o contrário. Conforme a própria personagem nos diz na pág. 197, a respeito do nascimento de Rorschach, quando "Kovacs mascarado", "fingindo ser Rorschach" mata os cães que dividiam os restos mortais de Blaire Roche: "Foi Kovacs que disse 'Jesus', sob o látex. Foi Kovacs que fechou os olhos. Foi Rorschach quem abriu depois" (MOORE; GIBBONS, 2009, 197). E a questão entre homem e disfarce volta a ser explícita:

Minhas coisas estavam onde eu havia deixado. À minha espera. Colocando-as, abandonei o disfarce e voltei a ser eu mesmo, livre do medo, da fraqueza ou do desejo. Meu casaco, meus sapatos, minhas

Doutoranda em Psicologia Social da Universidade do Estado do Rio de Janeiro. Brasileira, residente em Rio de Janeiro- RJ. E-mail: taistania@gmail.com

Mestre em Letras pela Universidade Estadual de Mato Grosso do Sul. Brasileiro, residente em Campo Grande-MS. E-mail: gmlimaleal@gmail.com

Doutorando em Letras da Universidade Federal de Mato Grosso do Sul. Brasileiro, residente em Campo Grande - MS. E-mail: tutor.franjotti@gmail.com 
luvas imaculadas. Meu rosto. (MOORE; GIBBONS, 2009, 160, grifos nossos)

Kovacs passa a existir em um plano secundário, funcionando apenas como um disfarce para Rorschach.

Na primeira cena do livro nos deparamos com a figura de Kovacs enquanto lemos o diário de Rorschach. Ele está próximo do local em que O Comediante (Edward Morgan Blake) caiu após ser atirado da janela de seu apartamento, onde há já apenas o sangue na calçada, pois o corpo, conforme podemos apreender, já fora retirado. As equipes de investigação já se encontram no local e, inclusive, Kovacs aparece novamente, ouvindo a conversa dos agentes, no momento em que estes deixam o edifício.

Com a posterior entrada de Rorschach em cena, também investigando a morte de Blake, podemos perceber que a figura de Kovacs na primeira página, segurando uma placa de "O fim está próximo", serve ao mascarado como um pivô. Serve como um mediador necessário para colocar-se junto às multidões - como apenas mais um transeunte - para, dessa forma, angariar insuspeitadamente informações que serão posteriormente utilizadas por Rorschach, que age a partir de fora da multidão, às escusas.

Esse expediente, mais do que revelar o duplo da personagem, nos dá um traço de ação único que liga os seus extremos em prol das atividades do anti-herói mascarado. O que significa dizer que, para si, a personagem tem o seu norte psicológico situado na faceta mascarada, não no cidadão, ao contrário, por exemplo, do que acontece com o Coruja (Dan Dreiberg) e com Sally Júpiter II (Laurie Juspeczyk) e com o Ozymandias (Adrian Veidt), daí dizermos que o disfarce é o rosto sem máscara.

Podemos detectar facilmente na narrativa um aspecto maniqueísta na personagem. Essa polarização moral fica muito bem simbolizada em sua fala que trata do tecido, originalmente parte de um vestido, que deu origem à máscara:

1962. Encomenda especial pra vestido com o novo tecido criado pelo $\mathrm{Dr}$. Manhattan. Fluídos viscosos entre duas camadas de látex sensíveis a calor pressão. Cliente: uma jovem, nome italiano. Não levou o vestido.

Doutoranda em Psicologia Social da Universidade do Estado do Rio de Janeiro. Brasileira, residente em Rio de Janeiro- RJ. E-mail: taistania@gmail.com

Mestre em Letras pela Universidade Estadual de Mato Grosso do Sul. Brasileiro, residente em Campo Grande-MS. E-mail: gmlimaleal@gmail.com

Doutorando em Letras da Universidade Federal de Mato Grosso do Sul. Brasileiro, residente em Campo Grande - MS. E-mail: tutor.franjotti@gmail.com 
Disse que era feio. Errado. Não era nada feio. Um preto e branco que se movia, mudando a forma... Mas sem se mesclar. Nada de cinza. (MOORE; GIBBONS, 2009, 186, grifo nosso)

Esse maniqueísmo expresso esteticamente na máscara está presente ao longo de algumas passagens de modo mais aberto, como em "porque existe o bem e existe o mal. O mal deve ser punido. Mesmo no dia do juízo final isso não vai mudar" (MOORE; GIBBONS, 2009, 30). Ou seja, para ele não existe um meio termo, uma pessoa boa com contradições. Existe o preto e existe o branco, não o cinza, e por isso devemos ser julgados todos e direcionados à danação ou à redenção. O detalhe mais importante, no entanto, é como Rorschach se exclui desse todo que merece punição, o que já pode ser visto em trecho citado anteriormente ao referir-se às suas luvas como "imaculadas" e também de forma mais detectável em:

\footnotetext{
As ruas são sarjetas dilatadas e essas sarjetas estão cheias de sangue. Quando os bueiros finalmente transbordarem, todos os ratos irão se afogar. A imundície acumulada de todo o sexo e matanças que praticaram vai espumar até suas cinturas e todos os políticos e rameiras olharão pra cima, gritando "salve-nos"... ...e, do alto, eu vou sussurrar: "não". (MOORE; GIBBONS, 2009, 08)
}

Apesar de se imiscuir no submundo do crime, Rorschach está sempre fora dele, está sempre somente de visita, em busca de alguma informação ou de aplicar a alguém alguma punição. Rorschach é intrinsecamente externo ao julgamento porque é um instrumento da justiça, dessa moral maniqueísta que embasa seu próprio julgar, e como poderia um juiz condenar a si mesmo? Kovacs, inclusive, não é digno dessa exterioridade como é o Rorschach, tanto que a máscara é apenas "para conseguir se olhar no espelho" (MOORE; GIBOONS, 2009, 186), o que não conseguiria se ali visse esse homem comum, "gentil", ao invés do impiedoso juiz e executor Rorschach, homem sem meio-termo.

O capítulo VI do livro se intitula "O abismo também contempla" e trata da tentativa de compreensão de Rorschach por parte de um psicólogo da prisão em que se encontra. Esse capítulo possui um epíteto de Nietzsche: "Não enfrentes monstros sob pena de te tornares um deles, e se contemplas o abismo, a ti o Doutoranda em Psicologia Social da Universidade do Estado do Rio de Janeiro. Brasileira, residente em Rio de Janeiro- RJ. E-mail: taistania@gmail.com Mestre em Letras pela Universidade Estadual de Mato Grosso do Sul. Brasileiro, residente em Campo Grande-MS. E-mail: gmlimaleal@gmail.com

Doutorando em Letras da Universidade Federal de Mato Grosso do Sul. Brasileiro, residente em Campo Grande - MS. E-mail: tutor.franjotti@gmail.com 
abismo também contempla". Essa citação pode ser tomada como uma alegoria tanto da origem de Rorschach (em relação a Kovacs) como também do que ocorre ao psicólogo que tenta tratá-lo neste capítulo. Ele, o psicólogo, num primeiro momento se pergunta como fará para mostrar a seu paciente que o mundo não é como ele o enxerga com sua visão pessimista. Ele, portanto, não acredita que Rorschach esteja certo. Ao fim do capítulo, no entanto, o médico acaba se convencendo do contrário. Ao olhar a mancha de Rorschach, ele diz pra si:

\begin{abstract}
Tentei fingir que parecia uma árvore frondosa, com sombras sob ela, mas não consegui. A imagem lembrava o gato morto que um dia eu encontrei, as larvas gordas e cegas que rastejavam, abrindo túneis freneticamente para longe da luz. Mas mesmo essa imagem é para evitar o verdadeiro horror. O horror é este: ao final, tudo não passa de uma imagem de escuridão, vazia e sem sentido. Estamos sozinhos. Não existe mais nada. (MOORE; GIBBONS, 2009, 204, grifo nosso)
\end{abstract}

Held $(2009,29)$ nos diz que por trás das ações e da mente de Rorschach, há um princípio basilar muito simples: "o mal deve ser punido". Logo após, se utiliza da citação nietzschiana para propor uma reflexão acerca da conduta e da moral de Rorschach:

\footnotetext{
Por que o mal deve ser punido? Quem determina o que o mal é? Quem determina o que é uma punição apropriada ou adequada? E, em nossa missão para distribuir a justiça merecida, corremos o risco de nos tornar os monstros que combatemos? (HELD, 2009, 30)
}

Rorschach, esse maniqueísmo justiceiro e sedento de sangue (um monstro?), nasceu do contato com o próprio "rosto da cidade", torna-se perceptível que abandonou a identidade de Kovacs por ter entendido que o mundo não passava de um navio sem leme, que havia coisas que precisavam ser feitas, das quais um homem gentil como Kovacs não daria conta. A personagem deixa de ser homem e passa a ser um instrumento da justiça.

Conforme nos afirma, não foi possível permanecer incólume ante as atrocidades presenciadas. O que o resta, como dever, como mão cega que executa uma moral surda, é punir o mal, ainda que seja em uma situação onde se sabe que o que se pode fazer é pouco: "A cidade está morrendo de hidrofobia e Doutoranda em Psicologia Social da Universidade do Estado do Rio de Janeiro. Brasileira, residente em Rio de Janeiro- RJ. E-mail: taistania@gmail.com Mestre em Letras pela Universidade Estadual de Mato Grosso do Sul. Brasileiro, residente em Campo Grande-MS. E-mail: gmlimaleal@gmail.com

Doutorando em Letras da Universidade Federal de Mato Grosso do Sul. Brasileiro, residente em Campo Grande - MS. E-mail: tutor.franjotti@gmail.com 
tudo que consigo fazer é limpar um pouco da espuma de sua boca" (MOORE, 2009, 22).

Assume então a rotina de um vigilante. Ronda os locais públicos e costumeiros da cidade, como a banca de jornal, disfarçado de um cidadão normal, ou melhor, sem suspeitas, disfarçado de Kovacs. Mas o faz na verdade para ouvir conversas e levantar dados como observador, para que então possa surgir Rorschach, esse que é quem se arrisca a frequentar o submundo do crime e, o mais importante de tudo, agir em consonância com a 'justiça', executar as punições necessárias.

\section{FLÂNEUR}

O flâneur é uma figura, um tipo social, conceituada por Charles Baudelaire. Podemos dizer concisamente que consiste daquele que vaga, observa e reflete acerca, que se imiscui na multidão e tem um prazer próprio exatamente nisso, um vagar pela cidade e observar. O contexto de origem da flânerie (a atividade do flâneur) é a Paris do séc. XIX, com pessoas povoando com densidade as ruas da cidade, dando os contornos de multidão aos conjuntos de transeuntes, uma massa de pessoas totalmente heterogênea.

Desde então, há vasta bibliografia em torno dessa figura. Baudelaire evoca como local da flânerie principalmente a paisagem das galerias comerciais parisienses por onde o "flâneur idealmente passearia com uma tartaruga" (BENJAMIN, 1994, 50-51), alegoria da velocidade de sua marcha, de forma a poder apreciar os transeuntes, as vitrines, ter uma visão privilegiada desse grande conjunto orgânico que é a cidade moderna.

Essa velocidade, a da alegoria da tartaruga, é também uma provocação ao ritmo comercial burguês que toma conta do mundo: o flâneur é um desencaixado, um aristocrata sem título, um burguês sem empregados; enfim, pela própria natureza de suas andanças, conforme as ruas iam sendo cada vez mais densamente povoadas e conforme cada vez mais a burguesia tomava o lugar Doutoranda em Psicologia Social da Universidade do Estado do Rio de Janeiro. Brasileira, residente em Rio de Janeiro- RJ. E-mail: taistania@gmail.com Mestre em Letras pela Universidade Estadual de Mato Grosso do Sul. Brasileiro, residente em Campo Grande-MS. E-mail: gmlimaleal@gmail.com

Doutorando em Letras da Universidade Federal de Mato Grosso do Sul. Brasileiro, residente em Campo Grande - MS. E-mail: tutor.franjotti@gmail.com 
anteriormente ocupado pela aristocracia, o flâneur se torna uma imagem marginal, a atividade de flanar vai ficando cada vez mais mal quista pelos cidadãos de bem.

O flâneur encontra mais proximidade com outros tipos marginais como os trapeiros, os mendigos e as prostitutas do que com a burguesia ascendente ou com a aristocracia decadente, talvez justamente porque há em comum entre todos esses tipos o fato de viverem mormente suas vidas sob os olhos das grandes massas, em lugares públicos².

Uma diferenciação essencial que devemos fazer é a do flâneur com relação à figura do basbaque (ou, do francês, badaud). O basbaque igualmente é um observador anônimo da cidade, mas há um traço de diferença essencial entre ambos. O flâneur é essencialmente reflexivo, se dissolve na multidão como condição de lugar para observar, ou seja, apesar de estar "dentro" dela, conserva sempre uma faculdade de reflexão acerca do que observa. Como a reflexão não vem sem distanciamento essa faculdade o coloca simultaneamente numa posição externa - o flâneur é uma figura dialética. O basbaque se deixa enredar de todo pela multidão não restando reflexão alguma sobre o observado; há apenas o mero prazer proveniente do deixar-se levar pelo interminável fluxo da multidão:

\begin{abstract}
Não vamos, todavia, confundir o flanador com o badaud: há uma nuance... O simples flanador está sempre em plena posse de sua individualidade; a do badaud, ao contrário, desaparece absorvida pelo mundo exterior... que o impressiona até a embriaguez e o êxtase. Sob a influência do espetáculo que se oferece a ele, o badaud se torna um ser impessoal; já não é um ser humano; é o público, é a multidão. (FOURNEL apud BENJAMIN, 1994, 202)
\end{abstract}

O flâneur está ligado a todo tempo, conforme Baudelaire, a alguma função subsequente às suas deambulações citadinas - essas servem a ele como meio a sua atividade-fim, geralmente alguma produção artística, de forma que seus passeios seriam algo como uma retroalimentação.

\footnotetext{
2 Para mais informações acerca da marginalidade no flâneur, além do que fica evidente nas próprias Flores do mal ou em seus Pequenos poemas em prosa, Cf. The Flaneur's Relationship to Marginal Types in The Old Acrobat of Charles Baudelaire disponível em http://www.123HelpMe.com/view.asp?id=8129 acessado em 02/03/2015 às 10:33.

Doutoranda em Psicologia Social da Universidade do Estado do Rio de Janeiro. Brasileira, residente em Rio de Janeiro- RJ. E-mail: taistania@gmail.com

Mestre em Letras pela Universidade Estadual de Mato Grosso do Sul. Brasileiro, residente em Campo Grande-MS. E-mail: gmlimaleal@gmail.com

Doutorando em Letras da Universidade Federal de Mato Grosso do Sul. Brasileiro, residente em
} Campo Grande - MS. E-mail: tutor.franjotti@gmail.com 
No ensaio O pintor da vida moderna, há continuamente a lembrança de que - Sr. G. trabalha de maneira mnemônica: se utiliza de suas observações para pintar, o que faz recorrendo às lembranças coletadas nessas andanças pela cidade parisiense, quando já em casa, em frente ao material a ser trabalhado.

O flâneur é, portanto, um observador que reflete, toma notas do que observa no intento de desvelar a cidade por trás da cidade. É a serviço de uma lógica reflexiva e de conhecimento coletivo que está a atividade de perambular pela cidade.

\section{RORSCHACH: FLÂNEUR E ANTI-FLANEUR}

A noção do criminoso como um sujeito oculto entre tantos outros e, consequentemente, a de criminoso na cidade moderna, é tratada por Benjamin em seu ensaio Paris do segundo o império. Segundo ele a causa disso é justamente a novidade da noção de multidão, de convivência massificada da população, com tantos desconhecidos (quantos deles, criminosos em potencial?), conforme diz uma declaração de um agente secreto que transcreve em seu texto:

é quase impossível - escreve um agente secreto - manter boa conduta numa população densamente massificada, onde cada um é, por assim dizer, desconhecido de todos os demais e não precisa enrubescer na frente de ninguém. (apud BENJAMIN, 1994, 38)

A literatura policial surgiu justamente na época do adensamento populacional das cidades devido à industrialização, na primeira metade do século XIX. A partir daí podemos vislumbrar uma relação que se estabelece entre ambas, principalmente tendo-se em conta a citação acima: a multidão - os desconhecidos que dão "asilo (ao) anti-social e seus perseguidores" (BENJAMIN, 1994, 38). Poe finaliza seu conto $O$ Homem da Multidão, cujo protagonista é um flanêur, com um comentário sobre esse homem cuja silhueta se dissolve dentre outras tantas e

Doutoranda em Psicologia Social da Universidade do Estado do Rio de Janeiro. Brasileira, residente em Rio de Janeiro- RJ. E-mail: taistania@gmail.com

Mestre em Letras pela Universidade Estadual de Mato Grosso do Sul. Brasileiro, residente em Campo Grande-MS. E-mail: gmlimaleal@gmail.com

Doutorando em Letras da Universidade Federal de Mato Grosso do Sul. Brasileiro, residente em Campo Grande - MS. E-mail: tutor.franjotti@gmail.com 
que parece não conseguir encarar sua individualidade - ficar fora da multidão ele seria "o tipo e o gênio do crime profundo".

Com a aprovação da Lei Keene, em Watchmen, os mascarados foram proibidos de agir publicamente, restando aos que ainda se aventurassem a ilegalidade, de forma que, mesmo que seu intento fosse o combate ao crime, seriam eles, desde o colocar da máscara, criminosos, parte do que combatiam. De fato, essa contradição (e, é claro, o risco de punição legal) fez com que muitos abandonassem essa vida. Rorschach não foi um deles.

\section{CONCLUSÃO}

Kovacs, conforme vimos nas primeiras cenas do GN, se mostra esse criminoso disfarçado na multidão, o "gênio do crime profundo" de que fala Poe, uma vez que se utiliza do anonimato proporcionado pela grande massa disforme para coletar suas observações - combustível para as ações (criminosas) de Rorschach. Nesse sentido e, lembrando da arte mnemônica conforme descrita por Baudelaire - o resgate de todo o assistido por parte do artista-flâneur quando já em sua residência, em seu ateliê ou escrivaninha - chegamos à proximidade que há disso, o procedimento mnemônico do artista-flâneur, com o procedimento da personagem de Moore.

Ao passo que está passando despercebido, deixando entrar toda a luz pelo vidro dos olhos a atingir a memória, ele está abastecendo seu repertório de informações que utilizará nos julgamentos/execuções de Rorschach: um criminoso mascarado que desmascara os criminosos sem rosto que se escondem na amorfa massa populacional.

Se a atitude do flâneur é "um abreviado da atitude política das classes médias sob o segundo império" (BENJAMIN apud BOLLE, 2000, 372), período no qual a Era das Revoluções se choca com a Era do Capital (BOLLE, 2000, 381), podemos traçar um paralelo entre Rorschach e a visão do mundo da sociedade em Watchmen. Ante a guerra fria e ante a iminência de uma guerra nuclear nada mais natural às classes intermediárias do que o maniqueísmo, a divisão de tudo Doutoranda em Psicologia Social da Universidade do Estado do Rio de Janeiro. Brasileira, residente em Rio de Janeiro- RJ. E-mail: taistania@gmail.com Mestre em Letras pela Universidade Estadual de Mato Grosso do Sul. Brasileiro, residente em Campo Grande-MS. E-mail: gmlimaleal@gmail.com

Doutorando em Letras da Universidade Federal de Mato Grosso do Sul. Brasileiro, residente em Campo Grande - MS. E-mail: tutor.franjotti@gmail.com 
em dois opostos absolutos. Além de aproximar as figuras de Rorschach e do flâneur, esse reflexo do social serve ao primeiro, dentro da narrativa, como espécie de justificativa histórica para a polarização moral que sobre tudo exerce com seus julgamentos.

Com isso chegamos a uma contraposição após destacar as similitudes entre o flâneur e Kovacs/Rorschach: a moralidade. Pudemos perceber que este se vale de toda a sua flânerie em prol de uma atividade que neste está ausente: a interferência direta, sob preceitos morais, sobre a multidão e os homens que a constituem.

Se o flâneur (Kovacs) é necessariamente passivo nos meios por onde passa, Rorschach é o diametralmente oposto, toma como escolha moral o não assistir inerte às imoralidades que presencia. Se o máximo em que podiam desembocar as andanças e observações do flâneur eram obras de arte ou reflexões, fossem elas filosóficas, sociológicas ou estéticas, em Watchmen temos o flâneur como investigador à paisana.

Podemos, por fim, concluir que a (dupla) personagem de Moore se aproxima e se afasta dialeticamente da também dialética imagem do flâneur. Se Benjamin utiliza o flâneur como alegoria para a história desse período em sua obra sobre Paris, também o faz Moore em relação à história nesse período dos Estados Unidos da América (e porque não da história da humanidade?) o que tem êxito justamente pela justaposição das personagens Rorschach/Kovacs em uma única.

\section{REFERÊNCIAS}

BAUDELAIRE, Charles. O pintor da vida moderna. Belo Horizonte: Autêntica, 2010.

BENJAMIN, Walter. Charles Baudelaire um lírico no auge do capitalismo. 2 ed. Trad. José Carlos Martins Barbosa; Hemerson Alves Baptista. Rio de Janeiro: Brasiliense, 1994. (Obras escolhidas, 3).

Doutoranda em Psicologia Social da Universidade do Estado do Rio de Janeiro. Brasileira, residente em Rio de Janeiro- RJ. E-mail: taistania@gmail.com Mestre em Letras pela Universidade Estadual de Mato Grosso do Sul. Brasileiro, residente em Campo Grande-MS. E-mail: gmlimaleal@gmail.com

Doutorando em Letras da Universidade Federal de Mato Grosso do Sul. Brasileiro, residente em Campo Grande - MS. E-mail: tutor.franjotti@gmail.com 
BIONDILLO, Rosana, "O fantasma da mercadoria: uma leitura materialista do Flâneur benjaminiano" In__:Cadernos Walter Benjamin N. 16, Jan-Junho, Ano 2016, acessível no site: www.gewebe.com.br, pp. 58-71.

BOLLE, Willie. Fisiognomia da Metrópole Moderna: Representação da História em Walter Benjamin. 2 ed. São Paulo: Edusp, 2000.

HELD, Jacob M. Podemos conduzir este mundo sem leme? Kant, Rorschach, Retributivismo e Honra. In_: IRWIN, Willian; WHITE, Mark D. Watchmen e a Filosofia: um teste de Rorschach. São Paulo: Madras, 2009.

MOORE, Alan; GIBBONS, Dave. Watchmen. Sao Paulo: Panini Books, 2009.

PECCININI, Daisy V. M.; LEITE, Luciana de A. Pós-moderno: a problemática do pós-moderno no campo artístico. Disponível em: http://www.mac.usp.br/mac/templates/projetos/seculoxx/modulo6/posmoderno.ht $\underline{\mathrm{ml}}$ Acesso em 12 de julho de 2019, às 16:39.

POE, Edgar Alan. O Homem da multidão. In__: BAUDELAIRE, Charles. O pintor da vida moderna. Belo Horizonte: Autêntica, 2010.

Doutoranda em Psicologia Social da Universidade do Estado do Rio de Janeiro. Brasileira, residente em Rio de Janeiro- RJ. E-mail: taistania@gmail.com

Mestre em Letras pela Universidade Estadual de Mato Grosso do Sul. Brasileiro, residente em Campo Grande-MS. E-mail: gmlimaleal@gmail.com

Doutorando em Letras da Universidade Federal de Mato Grosso do Sul. Brasileiro, residente em Campo Grande - MS. E-mail: tutor.franjotti@gmail.com 